\title{
Factors Associated With Access to Dental Services of Adults With Physical Disabilities in Thailand
}

\author{
Nithimar Sermsuti-anuwat ${ }^{1} \&$ Sathirakorn Pongpanich ${ }^{1}$ \\ ${ }^{1}$ College of Public Health Sciences Chulalongkorn University, Bangkok 10330, Thailand \\ Correspondence: Nithimar Sermsuti-anuwat, College of Public Health Sciences Chulalongkorn University, \\ Phyathai Rd., Pathumwan, Bangkok 10330, Thailand. Tel: 662-218-8194. E-mail: nimar.or@gmail.com
}

Received: May 30, 2018 Accepted: July 22, 2018 Online Published: July 25, 2018

doi:10.5539/gjhs.v10n8p163 URL: https://doi.org/10.5539/gjhs.v10n8p163

\begin{abstract}
Objectives: To determine factors associated with access to dental services of community-dwelling adults with physical disabilities in Thailand.

Methods: This cross-sectional study was conducted at the Center of Independent Living, community club for individuals with disabilities in Pathum Thani province, Thailand, in February 2018. Individual participants were interviewed by a trained interviewer using a structured questionnaire that consisted of (1) questions on demographic characteristics and (2) adapted questions that were based on the modified Penchansky and Thomas's dimensions of access (accessibility, availability, acceptability, affordability, accommodation and awareness). Enter method of binary logistic regression analysis was used.
\end{abstract}

Results: We included 198 individuals with physical disabilities. Most participants had not attended dental care services in the previous 12 months (77.3\%) and gave negative responses for all questions regarding the dimensions of access. Although we did not observe any statistically significant differences in age and the six dimensions of access between participants who had attended at least one dental appointment and those who had not, in multivariate analysis, we found a statistically significant association indicated that participants who had education $\leq$ primary were 3.35 times more likely to had not attended at least one dental appointment $(p=0.002)$.

Conclusion: Our findings have uncovered factors associated with access to dental services of community-dwelling adults with physical disabilities in Thailand. Individuals with physical disabilities are in need of oral health education programs regarding proper oral health behaviors such as regular dental services attendance, appropriate oral hygiene practices and dental care benefits.

Keywords: barriers to care, dental service, physical disabilities, Thailand

\section{Introduction}

According to the 2012 national survey report of disability from the National Statistical Office of Thailand (NSO), (NSO, 2012) indicated that there are 1.5 million Thai individuals with disabilities, comprising an estimated 2.2\% of the total Thai population. Furthermore, the number increases among older Thai nationals (Khongboon, Pongpanich, \& Chapman, 2016). The main type of disability (nearly 50\%) is physical disabilities. Although $92.1 \%$ of disabled Thai citizens have healthcare benefits under the government universal health coverage (UC), $98.7 \%$ have current health problems (NSO, 2012).

Previous studies (Chimruang \& Sermsuti-anuwat, 2012; Kothari et al., 2017; Pan et al., 2017; Rashid-Kandvani, Nicolau, \& Bedos, 2015; Yuen et al., 2010) have reported that individuals with disabilities experience poorer oral health than individuals without disabilities, presenting with a greater number of dental cavities and increased risk of periodontal diseases. Good oral health is a basic human right, and disabled individuals are equally inclined to preserve their natural teeth for the same reasons as individuals without disabilities, including enjoyable eating, improved physical appearance, enhanced self-confidence, increased social acceptance, general well-being, and good quality of life (Dougall \& Fiske, 2008; Pan et al., 2017). Moreover, all individuals should have access healthcare systems and oral healthcare services of an equal quality to achieve equitable outcomes (Dougall \& Fiske, 2008; Rashid-Kandvani et al., 2015).

Thai individuals with disabilities may experience poor oral health but there has not yet been a national oral health survey of the disabled population of Thailand. As such, the difficulties accessing dental services among Thai adults 
with physical disabilities have not previously been identified.

Therefore, the purpose of this study was to determine factors associated with access to dental services of community-dwelling adults with physical disabilities in Thailand.

\section{Methods}

This cross-sectional study was conducted at the Center of Independent Living, community club for individuals with disabilities in Pathum Thani province, Thailand, between $1^{\text {st }}$ and $25^{\text {th }}$ February 2018 . The study protocol was approved by the Research Ethics Review Committee for Research Involving Human Research Participant, Health Sciences Group, Chulalongkorn University, Thailand (No.012/2018), which has approved in accordance with the International Conference on Harmonization - Good Clinical Practice (ICH-GCP). Informed consent was obtained for participation; the information sheets were read by one of the authors, assuring the comprehension of the information statement for all subjects. Participants signed to inform that their responses were anonymous and confidential.

\subsection{Participants}

The sample size was calculated using the formula that was developed by Cochran as mentioned in a prier study (Singh \& Masuku, 2014), when the utilization of dental health services from the annual health report (2017) of the Center for Independent Living (a disability community club) was 15\%, a convenient sample of 196 samples was required. All members of disability community clubs in Pathum Thani province, Thailand were invited to participate in the study. Men and women with physical disabilities were included if they were Thai citizens, aged 18-64 years, living in residential community households, capable of performing their own daily self-care independently with a score $\geq 12$ on the Thai Modified Barthel Activities of Daily Living (ADL) index of Department of Medical Services (DMS), Ministry of Public Health, Thailand (DMS, 2013). Exclusion criteria were: Thai people, who were identified on their Thai national identity card as mental complications, hearing loss, visual impairments, or reported serious chronic diseases; those who were unable to communicate in Thai language; and those unwilling to be a participant.

\subsection{Data Collection}

Individual participants were interviewed by a trained interviewer using a structured questionnaire that consisted of (1) questions on demographic characteristics (age, gender, income and education level) and (2) adapted questions that were based on the Penchansky and Thomas's dimensions of access (Penchansky \& Thomas, 1981) and the modified Penchansky and Thomas's theory of access (Saurman, 2016). The latter collected data regarding the following:

- Accessibility: "Is there a convenient dental service for individuals with physical disabilities in terms of location, time and distance?" (Yes/No)

- Availability: "Are there sufficient dental services and resources to meet the specific needs of individuals with physical disabilities and communities?" (Yes/No)

- Acceptability: "Do individuals with physical disabilities find dental service providers acceptable in terms of the characteristics of dental services, and social or cultural concerns?" (Yes/No)

- Affordability: "Is there an affordable dental service for individuals with physical disabilities?" (Yes/No)

- Accommodation: "Is there an adequate dental service that well organized for individuals with physical disabilities? Consideration of adequacy include hours of dental operation (after-hour dental services), referral or appointment systems, and facility structures (wheelchair access)." (Yes/No)

- Awareness: "Does dental care maintain awareness through effective communication and information strategies with relevant users (dentists, dental nurses, patients without disabilities, patients with disabilities and community), including consideration of context and oral health literacy?" (Yes/No)

Three experts in public health validated the contents of the adapted questionnaire through the index of Item-Objective Congruence, IOC $=0.84$. A pilot test of 30 individuals with physical disabilities from nearby community was conducted to test the internal consistency. The Cronbach's Alpha coefficient was 0.89.

\subsection{Data Analysis}

We compared demographic characteristics between participants who had at least one dental appointment and those who had not attended dental care in the previous year. We used medians, ranges, for non-normally distributed variable (Barthel ADL scores and age). Fisher's exact tests were calculated for categorical independent variables, those variables that presented $\mathrm{p}<0.25$ were included in logistic regression analyses. Enter method of binary 
logistic regression analysis was used; initial analyses for identified bivariate comparisons between dental service attendance and demographic characteristics (age, gender, income and education) including the dimensions of access variables (accessibility, availability, acceptability, affordability, accommodation, and awareness) were performed; the associated independent variables that showed p-value $<0.2$ were included in multivariate logistic regression analysis. Quantitative data were analyzed with SPSS software (version 20; IBM: Chicago, IL, USA). All analyses were two-tailed and a p-value $<0.05$ was considered statistically significant.

\section{Results}

Table 1 presents the demographic characteristics of the study participants. We included 198 individuals with physical disabilities who were capable of performing daily self-care with a median Barthel ADL score of 16 . Participants aged 21-62 years (median: 49 years) completed the structured questionnaires. Most participants had not attended dental care services in the previous 12 months (77.3\%).

For category variables, the major demographic characteristics of the study population aged $\geq 49$ years $(58.6 \%)$, male (63.6\%), income less than 15,000 THB (approximately 475 USD) per month (76.3\%), up to or less than primary school $(73.2 \%)$ and gave negative responses for questions regarding the dimensions of access (Penchansky \& Thomas, 1981; Saurman, 2016) as follows: 73.7\% of the study participants reported 'no accessible dental service', $71.7 \%$ reported 'no available dental service', $70.2 \%$ reported 'no acceptable dental service', $74.7 \%$ reported 'no affordable dental service', $78.8 \%$ reported 'no accommodating dental service', $77.8 \%$ reported 'no awareness in dental service'.

Table 1. Demographic characteristics of the study participants

\begin{tabular}{|c|c|c|}
\hline Variables & number or median (min-max) & percent or mean (SD) \\
\hline Total & 198 & 100 \\
\hline Barthel ADL scores & $16(12-19)$ & $15.81(2.17)$ \\
\hline Age (years) & $49(21-62)$ & $48.48(8.14)$ \\
\hline$<49$ years & 82 & 41.4 \\
\hline$\geq 49$ years & 116 & 58.6 \\
\hline \multicolumn{3}{|l|}{ Gender } \\
\hline Female & 72 & 36.4 \\
\hline Male & 126 & 63.6 \\
\hline \multicolumn{3}{|l|}{ Income per month } \\
\hline$\geq 15,000$ THB (475 USD) & 47 & 23.7 \\
\hline$<15,000$ THB & 151 & 76.3 \\
\hline \multicolumn{3}{|l|}{ Education } \\
\hline$>$ Primary & 53 & 26.8 \\
\hline$\leq$ Primary & 145 & 73.2 \\
\hline \multicolumn{3}{|l|}{ Attended dental service ${ }^{a}$} \\
\hline Yes & 45 & 22.7 \\
\hline No & 153 & 77.3 \\
\hline
\end{tabular}

\begin{tabular}{lll}
\hline $\begin{array}{l}\text { Dimensions of access }{ }^{\mathbf{b}} \\
\text { Accessibility }\end{array}$ & \\
Yes & 52 & 26.3 \\
No & 146 & 73.7 \\
\hline Availability & & \\
Yes & 56 & 28.3 \\
No & 142 & 71.7 \\
\hline
\end{tabular}




\begin{tabular}{lll}
\hline $\begin{array}{l}\text { Acceptability } \\
\text { Yes }\end{array}$ & 59 & 29.8 \\
No & 139 & 70.2 \\
\hline $\begin{array}{l}\text { Affordability } \\
\text { Yes }\end{array}$ & 50 & 25.3 \\
No & 148 & 74.7 \\
\hline Accommodation & 42 & 21.2 \\
Yes & 156 & 78.8 \\
No & 44 & 22.2 \\
\hline Awareness & 154 & 77.8 \\
Yes & No &
\end{tabular}

Note. All participants relied on government Universal Health Coverage including dental benefits

$\mathrm{ADL}=$ Activity of daily living

$\mathrm{SD}=$ Standard Deviation

$\min -\max =$ minimum-maximum

${ }^{\mathrm{a}}=$ Attended at least one dental care visiting

$\mathrm{b}=$ Dimensions of access.

In Table 2, although we did not observe any statistically significant differences in age and the six dimensions of access between those who had attended at least one dental appointment in the previous year and those who had not, there was a significant difference in education level between the two groups $(p=0.012)$; the independent variables that demonstrated $\mathrm{p}<0.25$ in the bivariate analyses were included in binary logistic regression analyses.

Table 2. Factors associated with dental services attendance within 12 months of the study participants

\begin{tabular}{|c|c|c|c|}
\hline \multirow{2}{*}{ Variables } & \multicolumn{2}{|c|}{ Attended at least one dental care service } & \multirow{2}{*}{ p-value } \\
\hline & Yes $^{a}$ & $\mathrm{No}^{a}$ & \\
\hline Total & $45(22.7)$ & $153(77.3)$ & \\
\hline \multicolumn{4}{|l|}{ Age (years) } \\
\hline$<49$ years & $24(53.3)$ & $58(37.9)$ & 0.085 \\
\hline$\geq 49$ years & $21(46.7)$ & $95(62.1)$ & \\
\hline \multicolumn{4}{|l|}{ Gender } \\
\hline Female & $18(40)$ & $54(35.3)$ & 0.599 \\
\hline Male & $27(60)$ & $99(64.7)$ & \\
\hline \multicolumn{4}{|l|}{ Income per month } \\
\hline$\geq 15,000$ THB (475 USD) & $9(20.0)$ & $38(24.8)$ & 0.556 \\
\hline$<15,000$ THB & $36(80.0)$ & $115(75.2)$ & \\
\hline \multicolumn{4}{|l|}{ Education } \\
\hline$>$ Primary & $19(42.2)$ & $34(22.2)$ & 0.012 \\
\hline$\leq$ Primary & $26(57.8)$ & $119(77.8)$ & \\
\hline
\end{tabular}


Dimensions of access $^{c}$

\begin{tabular}{|c|c|c|c|}
\hline \multicolumn{4}{|c|}{ Accessibility } \\
\hline Yes & $16(35.6)$ & $36(23.5)$ & 0.124 \\
\hline No & $29(64.4)$ & 117 (76.5) & \\
\hline \multicolumn{4}{|c|}{ Availability } \\
\hline Yes & $17(37.8)$ & $39(25.5)$ & 0.132 \\
\hline No & $28(62.2)$ & $114(74.5)$ & \\
\hline \multicolumn{4}{|c|}{ Acceptability } \\
\hline Yes & $18(40.0)$ & $41(26.8)$ & 0.098 \\
\hline No & $27(60.0)$ & $112(73.2)$ & \\
\hline \multicolumn{4}{|c|}{ Affordability } \\
\hline Yes & $15(33.3)$ & 35 (22.9) & 0.174 \\
\hline No & $30(66.7)$ & $118(77.1)$ & \\
\hline \multicolumn{4}{|c|}{ Accommodation } \\
\hline Yes & $13(28.9)$ & $29(19.0)$ & 0.153 \\
\hline No & $32(71.1)$ & $124(81.0)$ & \\
\hline \multicolumn{4}{|c|}{ Awareness } \\
\hline Yes & $14(31.1)$ & 30 (19.6) & 0.108 \\
\hline No & $31(68.9)$ & $123(80.4)$ & \\
\hline
\end{tabular}

Note. ${ }^{\mathrm{a}}=$ Number $(\%)$;

${ }^{\mathrm{b}}=$ Statistical calculation by Fisher's Exact Test;

${ }^{c}=$ Dimensions of access.

Results of simple bivariate and multivariate logistic regression analyses are presented in Table 3, the simple bivariate analyses showed the Odds ratio and $95 \%$ confidence interval (OR, 95\% CI) with $\mathrm{p}<0.2$ between dental service attendance and age group (OR: 1.87, 95\%CI: $0.96-3.66$ ), education level (OR: 2.56, 95\%CI: $1.27-5.17$ ) including all dimensions of access as accessibility (OR:1.79, 95\%CI: $0.88-3.67)$, availability (OR:1.78, 95\%CI: $0.88-3.59$ ), acceptability (OR:1.82, 95\%CI: $0.91-3.65$ ), affordability (OR:1.69, 95\%CI: $0.82-3.48$ ), accommodation (OR:1.74, 95\%CI: $0.81-3.72$ ), and awareness (OR:1.85, 95\%CI: $0.88-3.90$ ), then multivariate logistic regression analysis was performed.

For multivariate analysis, we found a statistically significant association that indicated participants who had education level $\leq$ primary education were 3.35 times more likely to had not attended at least one dental appointment in the previous year (OR: $3.35,95 \% \mathrm{CI}: 1.57-7.16$ ). 
Table 3. Simple bivariate and multivariate binary logistic regression analyses of dental services attendance of study participants

\begin{tabular}{|c|c|c|c|}
\hline Variables & Crude OR (95\%CI) & Adjusted OR (95\%CI) & p- value ${ }^{a}$ \\
\hline \multicolumn{4}{|l|}{ Age } \\
\hline$<49$ years (Ref) & 1 & 1 & \\
\hline$\geq 49$ years & $1.87(0.96-3.66)$ & $1.87(0.90-3.90)$ & 0.093 \\
\hline \multicolumn{4}{|l|}{ Gender } \\
\hline Female (Ref) & 1 & & \\
\hline Male & $1.22(0.62-2.42)$ & N/A & N/A \\
\hline \multicolumn{4}{|l|}{ Income per month } \\
\hline$>$ 15,000 THB (Ref) & 1 & & \\
\hline$<15,000$ THB & $0.76(0.33-1.71)$ & N/A & N/A \\
\hline \multicolumn{4}{|l|}{ Education } \\
\hline > Primary (Ref) & 1 & 1 & \\
\hline$\leq$ Primary & $2.56(1.27-5.17)$ & $3.35(1.57-7.16)$ & 0.002 \\
\hline \multicolumn{4}{|l|}{ Dimensions of access } \\
\hline \multicolumn{4}{|l|}{ Accessibility } \\
\hline Yes (Ref) & 1 & 1 & \\
\hline No & $1.79(0.88-3.67)$ & $0.96(0.19-4.88)$ & 0.957 \\
\hline \multicolumn{4}{|l|}{ Availability } \\
\hline Yes (Ref) & 1 & 1 & \\
\hline No & $1.78(0.88-3.59)$ & $1.49(0.26-8.42)$ & 0.655 \\
\hline \multicolumn{4}{|l|}{ Acceptability } \\
\hline Yes (Ref) & 1 & 1 & \\
\hline No & $1.82(0.91-3.65)$ & $1.18(0.36-3.88)$ & 0.791 \\
\hline \multicolumn{4}{|l|}{ Affordability } \\
\hline Yes (Ref) & 1 & 1 & \\
\hline No & $1.69(0.82-3.48)$ & $0.91(0.29-2.82)$ & 0.864 \\
\hline \multicolumn{4}{|l|}{ Accommodation } \\
\hline Yes (Ref) & 1 & 1 & \\
\hline No & $1.74(0.81-3.72)$ & $0.87(0.23-3.26)$ & 0.830 \\
\hline \multicolumn{4}{|l|}{ Awareness } \\
\hline Yes (Ref) & 1 & 1 & \\
\hline No & $1.85(0.88-3.90)$ & $2.07(0.59-7.22)$ & 0.256 \\
\hline
\end{tabular}

Note. The sample size was $\mathrm{n}=198$;

OR $=$ Odds Ratio;

$\mathrm{CI}=$ Confidence Interval;

Ref $=$ Reference group;

$\mathrm{N} / \mathrm{A}=$ Variables were not included into multivariate logistic regressions;

${ }^{\mathrm{a}}=\mathrm{p}$-value for multivariate logistic regressions; constant $=-0.647$. 


\section{Discussion}

To our best knowledge, this study presents the first scientific evidence of the factors associated with access to dental services of community-dwelling adults with physical disabilities in Thailand. The participants were independent, community-dwelling individuals, who were less likely to have a dental appointment, (Pradhan, Slade, \& Spencer, 2009) and therefore they may possibly be at a higher risk for oral diseases (Pan et al., 2017). Although all participants in this study relied on the government's UC scheme, the majority had irregular dental service attendance.

Furthermore, when compared to the Thai middle aged population without disabilities, according to the report of Thailand oral health national survey 2012 from the Ministry of Public Health (MOPH), Thailand (MOPH, 2012), the prevalence of Thai adults without disability who did not had dental care service within previous 12 months was $62.1 \%$ and irregular dental attendance among this study participants was $77.3 \%$.

Simple bivariate and multivariate analyses presented the significant associations between dental service attendance and education level (Table 3). We found that participants who had education level $\leq$ primary education were more likely to had not attended at least one dental appointment in the previous year. This finding was consistent with existing studies that have reported that more highly educated individuals are more likely to have regularly attend dental services (Chimruang \& Sermsuti-anuwat, 2012; Guiney, Woods, Whelton, \& Morgan, 2011; Van der Heyden, Demarest, Tafforeau, \& Van Oyen, 2003).

In Thailand, nearly $60 \%$ of Thai persons with disabilities have education less than primary education (NSO, 2012); evidence suggests that Thai persons with disabilities including physical disabilities possibly experience barriers to accessing dental care services (Chimruang \& Sermsuti-anuwat, 2012). This Thai context finding was consistent with previous studies of other countries, the higher education induces basic literacy skills and health related knowledge that can improve oral health accessibility because persons can realize the importance of good oral health and their appropriate options for dental care services (Tellez, Zini, \& Estupiñan-Day, 2014) such as a study of Ireland on predictors of accessing dental services indicates that higher education was one of the predictors of using dental services among their study participants (Guiney et al., 2011); a study of Belgium on the differences in demographic determinants and health services accessibility, they found persons with a higher education and income report more often dental care visiting (Van der Heyden et al., 2003).

Even though bivariate analysis (Table 3) showed relations between dental service attendance and all the dimensions of access (accessibility, availability, acceptability, affordability, accommodation, and awareness) with p-value less than 0.16 , there was no significant association in the multivariate analyses.

Regarding the dimensions of access (Penchansky \& Thomas, 1981; Saurman, 2016), for 'accessibility' (location, distance, and time), participants in this study were individuals with physical disability and required support from their family and friends for transportation. Therefore, participants preferred to use healthcare services, including dental services, in their community. However, most community hospitals in Thailand (health promoting hospitals) provide primary healthcare and are likely not equipped for special care dentistry. Thai individuals with disabilities have to travel more longer distance for their special needs dental care at secondary or tertiary care hospitals (Chimruang \& Sermsuti-anuwat, 2012). Our findings are similar to those reported in earlier studies, (Pradhan et al., 2009; Rashid-Kandvani et al., 2015; Yuen et al., 2010) which suggest that disabled individuals tend to have difficulties with travelling and transportation for dental healthcare.

The 'availability' dimension relates to the adequacy of dental staff and the presence of appropriate resources for individuals with physical disabilities. Most participants reported negative experiences in this dimension. These findings are consistent with observations of dentists' views reported in a previous study (Burapholkul, 2008) indicating a lack of specialty skills and the limited workplace facilities of dental service for people with disabilities in Thailand. Moreover, an earlier study (Pradhan et al., 2009) also mentions insufficient trained special care dentists as a notable barrier of access to dental services among disabled individuals. Therefore, some existing studies (Dao, Zwetchkenbaum, \& Inglehart, 2005; Faulks, Freedman, Thompson, Sagheri, \& Dougall, 2012; Saruta Saengtipbovorn, Surasak Taneepanichskul, Sathirakorn Pongpanich, \& Boonyamanond, 2012) have suggested that it is important for dental staffs to develop the essential skills and sufficient experience treating individuals with special needs to ensure access for all to oral healthcare.

'Acceptability' refers to the participants' attitudes towards dental staff. Most of participants reported negative responses. A prior study (Burapholkul, 2008) reports that Thai dental staffs are worried about difficulties in communication and behavioral management for disabled patients. Moreover, a well-organized consultation system for special care dentistry has not been established in Thailand (Burapholkul, 2008; Chimruang \& Sermsuti-anuwat, 
2012; Saruta Saengtipbovorn et al., 2012).

We also investigated 'affordability', it should be noted that Thai citizens with disabilities rely on the government UC scheme. Therefore, they are entitled to receive primary dental care services, such as tooth extraction, tooth filling, preventive dentistry, dental prophylaxis, and acrylic dentures (Chimruang \& Sermsuti-anuwat, 2012). The Thai government also provide support for individuals with disabilities in terms of public transportation. Nevertheless, most participants reported unaffordable dental service. This finding was consistent with previous studies reports of insufficient dental insurance, expensive dental procedures and high private transportation fees (Pradhan et al., 2009; Rashid-Kandvani et al., 2015; Rouleau et al., 2011).

'Accommodation' represents whether dental services are well organized for the use of persons with physical disabilities, and most of our participants reported negative experiences in this dimension. This is consistent with several previous studies (Leal Rocha, Vieira de Lima Saintrain, \& Pimentel Gomes Fernandes Vieira-Meyer, 2015; Pradhan et al., 2009; Rashid-Kandvani et al., 2015; Rouleau et al., 2011; Yuen et al., 2010) which have reported several difficulties of access to dental services among individual with physical disabilities including, inappropriate appointment systems, limited numbers of dental cases per day, poor referral systems, and architectural barriers. In Thailand, these reflections can be explained by a lack of specific policy on dental services for individuals with disabilities as suggested in a previous paper (Burapholkul, 2008) a cross-sectional study that reported the perspectives of Thai dentists.

'Awareness' refers to the provision of information and oral health literacy. Some studies(Guiney et al., 2011; Van der Heyden et al., 2003) have reported that more highly educated individuals are more likely regularly attend dental services. Moreover, a few studies (Holtzman, Atchison, Gironda, Radbod, \& Gornbein, 2014; McQuistan, 2017) have reported an association between limited oral health literacy and a greater risk of missed dental appointments. Those results were consistent with this study, most of participants had an education level lower than primary education and had not attended dental appointments within the previous 12 months.

\section{Limitations}

This study is subject to limitations. Although the findings have uncovered factors associated with access to dental services of community-dwelling adults with physical disabilities in Thailand, it is important to note that they may not be representative of all Thai people with disabilities. This cross-sectional study including the inability to investigate causality, small sample size and the weakness of the self-report questionnaire. Consequently, a large-scale quantitative study and a qualitative study of this topic among various disabilities are recommended.

\section{Conclusions}

Individuals with physical disabilities are in need of oral health education programs regarding proper oral health behaviors such as regular dental services attendance, appropriate oral hygiene practices and dental care benefits. Policy makers and oral health professionals in oral health system should be alerted to the explicit barriers reported such that equitable and equal dental services for disabled individuals can be developed.

\section{Acknowledgments}

This study was supported by the 90th Anniversary of Chulalongkorn University Fund (Ratchadaphiseksomphot Endowment Fund) GCUGR1125612051D, Chulalongkorn University, Bangkok, Thailand.

\section{Competing Interests Statement}

No conflicts of interest have been declared.

\section{References}

Burapholkul, P. (2008). Limitations and barriers of dentists to dental care for people with intellctual disability in Thailand. Thailand Journal of Dental Public Health, 13(5), 7-16.

Chimruang, J., \& Sermsuti-anuwat, N. (2012). Scoping Review and Research Synthesis on the Financial Management of Oral Health Promotion System for the Disabled in Thailand. Journal of Health Systems Research, 6(2), 278-289.

Dao, L. P., Zwetchkenbaum, S., \& Inglehart, M. R. (2005). General dentists and special needs patients: does dental education matter? J Dent Educ, 69(10), 1107-1115.

DMS. (2013). Guidelines for the elderly clinic (pp. 12-13): Department of Medical Services (DMS), Ministry of Public Health, Thailand. Retrieved from http://www.msd.bangkok.go.th/manual\% 20clinic\%20older\%20people.pdf. 
Dougall, A., \& Fiske, J. (2008). Access to special care dentistry, part 1. Access. Br Dent J, 204(11), 605-616. https://doi.org/10.1038/sj.bdj.2008.457

Faulks, D., Freedman, L., Thompson, S., Sagheri, D., \& Dougall, A. (2012). The value of education in special care dentistry as a means of reducing inequalities in oral health. Eur J Dent Educ, 16(4), 195-201. https://doi.org/10.1111/j.1600-0579.2012.00736.x

Guiney, H., Woods, N., Whelton, H., \& Morgan, K. (2011). Predictors of utilisation of dental care services in a nationally representative sample of adults. Community Dent Health, 28(4), 269-273.

Holtzman, J. S., Atchison, K. A., Gironda, M. W., Radbod, R., \& Gornbein, J. (2014). The association between oral health literacy and failed appointments in adults attending a university-based general dental clinic. Community Dent Oral Epidemiol, 42(3), 263-270. https://doi.org/10.1111/cdoe.12089

Khongboon, P., Pongpanich, S., \& Chapman, R. S. (2016). Risk Factors for Six Types of Disability among the Older People in Thailand in 2002, 2007, and 2011. J Aging Res, 2016, 6475029. https://doi.org/10.1155/2016/6475029

Kothari, M., Pillai, R. S., Kothari, S. F., Spin-Neto, R., Kumar, A., \& Nielsen, J. F. (2017). Oral health status in patients with acquired brain injury: a systematic review. Oral Surg Oral Med Oral Pathol Oral Radiol, 123(2), 205-219.e207. https://doi.org/10.1016/j.oooo.2016.10.024

Leal Rocha, L., Vieira de Lima Saintrain, M., \& Pimentel Gomes Fernandes Vieira-Meyer, A. (2015). Access to dental public services by disabled persons. Bmc Oral Health, 15, 35. https://doi.org/10.1186/s12903-015-0022-x

McQuistan, M. R. (2017). Poor Oral Health Literacy May Lead to Missed Dental Appointments. J Evid Based Dent Pract, 17(4), 422-424. https://doi.org/10.1016/j.jebdp.2017.10.002

MOPH. (2012). Thailand National Oral health Survey Report. Retrieved from http://dental.anamai.moph.go.th/elderly/academic/full99.pdf

NSO. (2012). The 2012 Disability Thailand National Survey. National Statistical Office (NSO), Ministry of information and communication technology, Thailand. Retrieved from http://service.nso.go.th/nso/nsopublish/service/survey/disabilityRep_55.pdf.

Pan, M. Y., Hsieh, T. C., Tai, H. C., Lin, M. S., Lin, Y. C., \& Chen, M. Y. (2017). Prevalence of and factors associated with fewer than 20 remaining teeth in Taiwanese adults with disabilities: a community-based cross-sectional study. BMJ Open, 7(10), e016270. https://doi.org/10.1136/bmjopen-2017-016270

Penchansky, R., \& Thomas, J. W. (1981). The concept of access: definition and relationship to consumer satisfaction. Med Care, 19(2), 127-140. https://doi.org/10.1097/00005650-198102000-00001

Pradhan, A., Slade, G. D., \& Spencer, A. J. (2009). Access to dental care among adults with physical and intellectual disabilities: residence factors. Aust Dent $J$, 54(3), 204-211. https://doi.org/10.1111/j.1834-7819.2009.01120.x

Rashid-Kandvani, F., Nicolau, B., \& Bedos, C. (2015). Access to Dental Services for People Using a Wheelchair. Am J Public Health, 105(11), 2312-2317. https://doi.org/10.2105/AJPH.2015.302686

Rouleau, T., Harrington, A., Brennan, M., Hammond, F., Hirsch, M., Nussbaum, M., \& Bockenek, W. (2011). Receipt of dental care and barriers encountered by persons with disabilities. Spec Care Dentist, 31(2), 63-67. https://doi.org/10.1111/j.1754-4505.2011.00178.x

Saruta Saengtipbovorn, Surasak Taneepanichskul, Sathirakorn Pongpanich, \& Boonyamanond, L. (2012). Factors associated with the utilization of dental health services by the elderly patients in health center no.54, Bangkok, Thailand. Journal of health research, 26(4), 199-204.

Saurman, E. (2016). Improving access: modifying Penchansky and Thomas's Theory of Access. J Health Serv Res Policy, 21(1), 36-39. https://doi.org/10.1177/1355819615600001

Singh, A. S., \& Masuku, M. B. (2014). Sampling Techniques \& Determination of Sample Size In Applied Statistics Research: An Overview. International Journal of Economics, Commerce and Management, II(11).

Tellez, M., Zini, A., \& Estupi-an-Day, S. (2014). Social Determinants and Oral Health: An Update. Current Oral Health Reports, 1(3), 148-152. https://doi.org/10.1007/s40496-014-0019-6

Van der Heyden, J. H., Demarest, S., Tafforeau, J., \& Van Oyen, H. (2003). Socio-economic differences in the utilisation of health services in Belgium. Health Policy, 65(2), 153-165. 
https://doi.org/10.1016/S0168-8510(02)00213-0

Yuen, H. K., Wolf, B. J., Bandyopadhyay, D., Magruder, K. M., Selassie, A. W., \& Salinas, C. F. (2010). Factors that limit access to dental care for adults with spinal cord injury. Spec Care Dentist, 30(4), 151-156. https://doi.org/10.1111/j.1754-4505.2010.00146.x

\section{Copyrights}

Copyright for this article is retained by the author(s), with first publication rights granted to the journal.

This is an open-access article distributed under the terms and conditions of the Creative Commons Attribution license (http://creativecommons.org/licenses/by/4.0/). 